\title{
The Justificatory Argument for Redistribution and Welfare State
}

\author{
Yixin Chen ${ }^{1}$ \\ ${ }^{1}$ School of Philosophy, Beijing Normal University, Beijing, China \\ Correspondence: Yixin Chen. E-mail: yixinchen@mail.bnu.edu.cn
}

Received: October 17, 2020

Accepted: October 26, 2020

Online Published: November 30, 2020

doi:10.5539/ass.v16n12p1

URL: https://doi.org/10.5539/ass.v16n12p1

\begin{abstract}
There is a dispute between welfare liberals and libertarians about whether redistribution of wealth is a rights violation. Welfare liberals believe that a state should redistribute income and wealth. In contrast, libertarians think redistribution is an intervention and a rights violation to the people who earn money in a free market by their inheritance or gifts. In the debate between Rawls and Nozick, there are two main disagreements about the liberty of whom and to what extent natural talents should be considered a shared asset by a state. MacIntyre thinks that Rawls and Nozick's moral debate is meaningless since there is conceptual incommensurability of the rival arguments in it. His resolution offers a virtue ethics perspective to be a reconciliation, which fails to provide a universal moral principle in a multicultural world. However, a new way to understand the concept of labor seems to give a justificatory argument for redistribution and welfare state.
\end{abstract}

Keywords: welfare liberalism, libertarianism, virtue ethics, liberty, equality

\section{Introduction}

There is a dispute between welfare liberals and libertarians about whether redistribution of wealth is a rights violation. Welfare liberals think that a state should redistribute income and wealth. The advantaged group's tax should be used to bridge the gap between rich and poor by helping the disadvantaged. In contrast, libertarians think redistribution is an intervention and a rights violation to the people who earn money in a free market by their inheritance or gifts. Both sides put forward their ideas for how to construct a fair society to guarantee citizens' rights.

The debate between Rawls, a welfare liberal, and Nozick, a libertarian, has been the most widely discussed. Nozick and Rawls both want to design a just society in which individuals participating in social exchanges would be treated fairly. Their disagreement, however, is whether the state should redistribute the talents of individuals as resources and services to others. Nozick believes that a just social structure should be in a minimal state where people have the right to their talents and can be allowed to get a fair share of a fair deal for their capabilities and good services. (Nozick, 2001) However, Rawls pays more attention to social welfare, believing that talent is the collective wealth and that differences in natural gifts should not lead to differences in people's possession. (Rawls, 1971)

This dispute shows the debate of negative right and positive right. Libertarians use non-interference as the main argument against welfare liberals, while welfare liberals think the no constraints to the rich's liberty means interference with the poor's liberty. Jan Narveson and James P. Sterba both approach the problem from a contractarian perspective. Narveson takes the political ideal of liberty to be a negative right to non-interference. (Narveson, 2010) In contrast, Sterba claims that an ideal of negative liberty ought to lead to substantial equality, because the recognition of a negative liberty will give rise to a positive right to welfare. (Sterba, 2009)

My strategy to support welfare liberals is to examine whether Nozick's critique of Rawls is successful and point out his theory's flaw, then try to resolve the dispute of libertarians and welfare liberals and defend the proposition that individuals deserve their natural qualifications under a specific moral constraint.

\section{Nozick's Criticism of Rawls and the Flaw}

Rawls assumes the "original position" as a "veil of ignorance", where the participants are required to assume that they do not know their social status or class, their natural abilities, aversion to risk, generational position, or conception of the good. The process of selection under the veil of ignorance is that the rational and self-interested individuals, who do not know their future social or occupational position, would not choose 
institutional arrangements in which a majority of the population benefit at the expense of a minority, because they do not know in which of the two groups they will reside. They would not select arrangements that will only favor their interests; instead, they would prefer an outcome that will be acceptable to any individual irrespective of their personal characteristics or social position. (Meadowcroft, 2011, pp. 171-172) Rawls argues that individuals in the original position will agree to organize society according to two basic principles: the liberty principle and the difference principle, respectively. The difference principle, sets out the basis upon which deviations from equality of income and wealth may be considered legitimate, is more controversial. As Vallentyne analyzes, Nozick holds that rights are absolute (with one possible exception). Nozick denies, on substantive grounds, that rights are ever permissibly infringed. (Vallentyne, 2011, p. 148)

Nozick gives objections to the presupposition of the veil of ignorance and doubts that people who have talents or inheritance would willingly become participants in Rawls's thought experiment and agree with the principle derived from it. He thinks that the real society is not apportioned according to a moral pattern but according to people exchanging goods and services. He believes that the problem with patterned principles is that "no end-state principle or distributional patterned principle of justice can be continuously realized without continuous interference with people's lives". (Nozick, 2001, p. 163)

Compared to Rawls's presupposition of the original position, Nozick calls entitlement theory historical but not patterned. He shows a version of the entitlement theory, which is based on an ideal of voluntarism. Nozick believes that distribution is legitimate if it arises by just steps from a just initial position, where the paradigm of a just step is voluntary exchange. As an exemplar of the kind of society that would go in line with his brand of entitlement theory, Nozick offers the ideal of a free market society governed by a minimal state which only has the function of keeping the peace and defending its borders. This minimal state has three features: Firstly, in such a society, people interact by consent and on mutually agreeable terms; secondly, people amass wealth in proportion to their ability to provide goods at prices that make their customers better off; thirdly, the three principles, which are the principles of initial acquisition, the principle of transfer, and the principle of rectification, should examine the whole transfer process of goods or services to guarantee its fairness.

Nozick succeeds in pointing out the idealization of the veil of ignorance since Rawls's presupposition is more like a thought experiment than a case that will happen in real life. It is impossible for people from different social positions and have diverse natural talents to wipe their memory or force them to be under the veil of ignorance. Rawls' theory is only a model to justify a welfare society and a possible reversion to the free market. From Nozick's view, it is hard to imply Rawls's model to capitalist society, and this redistribution model is a conflict with people's rights to their entitlements. However, he fails to recognize that the rights which a free market claims to provide cannot lead to a fair society.

Firstly, his principle of justice is unfair to the later comer. Principles of initial acquisition explain how a person or group legitimately could acquire something that had no previous owner. Nozick argues that people should be allowed to entitle their possession as long as they use their labor to obtain it legally. Previously unclaimed land is a historically prominent example, as are inventions and other intellectual property. But the unfair fact is that the land resources occupied by the previous generation will consume the resources of those who come after.

Another example is the unequal opportunity in the workplace. Under a specific production capacity in a society, the solidification of social positions occupied by predecessors will lead to the lack of fair competition among successors. Nozick may argue that people who came first have devoted more labor, have more experience, and better service to the market than those who came after them, so they deserve more. However, this advantage is not the result of efforts or even talents, but from deference of the time occupation. It is unfair to the people who come later to farm the land or find a job in the market because they don't have equal opportunities under the free market's rules.

Secondly, even though justice in transfer principle, specifying the conditions under which an individual who has rights over a thing can transfer those rights to another, protect the possessor's personal will, it would lead to an inequality in the market. Under capitalism, more capital means more opportunities to invest and more opportunities to accumulate wealth. Inheritances undoubtedly make some people born with more capital than others. Even with excellent investment skills, poor people may miss many opportunities to make money because of a lack of funds. That is not fair to the poor. A just society is not one that allows people's lives to be a gamble, but one that maximizes the possibility for those with bad luck to live with dignity through their efforts.

Nozick imagines a fair and voluntarily formed distribution system where every distribution arises from a prior just distribution in the transfer. However, in the real world, many transactions which appear to be just turn out to be unjust. Nozick offers rectification principles, which specify what to do about cases of wrongful acquisition or 
transfer, to guarantee that people's rights can be protected in virtue of past injustice. From Nozick's point of view, a trade that appears to be just now, but financed by the wealth generated by a previous unjust exchange, needs to be corrected. But what is the standard of correction? Should the wealth generated by the latter fair deal be confiscated altogether? This transfer seems unreasonable considering that this labor transfer involves the trader's efforts, despite the original capital accumulated through the previous labor-capital exchange. What standard should we use to determine how much a trader should get in a second fair trade? Besides, history shows that it usually took a while for the whole society to realize that a specific deal is unfair. Usually, people cannot immediately realize the information asymmetry between buyers and sellers or deception in the market. Thus, they fail to prevent the procession obtained from an unfair deal from being used in the second transfer. What is worse, via more transfers, this unfair original capital expands at an unpredictable pace, exacerbating the injustice of distribution in the market.

\section{The Dispute of the Right to Liberty and the Right to Equality}

As a representative of welfare liberals, Rawls uses the model of a veil of ignorance to argue the justification of this interference. His theory of justice is founded upon a particular model of the social contract in which individuals are assumed to enter an original position. In this scenario, individuals will agree with the institutional arrangements that will govern their closed society from the present time.

Rawls's model's original position, which requires people to decide an ideal social structure without knowing their talents or social classes, is to erase the wealth differences derived from people's accidents of natural endowment and the contingencies of social circumstance. Rawls thinks that a fair society should try the best to eliminate the wealth difference derived from innate talent or inheritance. He says: "the natural distribution is neither just nor unjust; nor is it unjust that persons are born into society at some particular position. These are simply natural facts. What is just and unjust is the way that institutions deal with these facts". (Rawls, 1971, p. 102)

However, even though Rawls does not approve the absolute economic equality because differential rewards may be needed to incentivize the most productive members of society to contribute to the generation of wealth, his theory of equality is still criticized as rights violation by libertarians, who worries that someone or some group has deliberately decided what income and wealth each individual or family should receive via so-called distribution justice.

Nozick is one of the libertarians who challenges Rawls's model by his entitlement theory and shows another possibility of how a just society forms and what structure this society should have. He accounts for how the minimal state can arise without violating anyone's rights and consider it an inspiring ideal. People can pursue their many different conceptions of the good life. It seems just that people hold on to the right to their possessions as long as it comes from a legal procedure. In his Chamberlain example, this famous basketball player provides the service, and the audience voluntarily pays. Chamberlain agrees to play basketball in return for 25 cents from each spectator, and the spectators voluntarily agree. Suppose that a million fans voluntarily purchase tickets over the course of the season, and there are no other financial transactions. Chamberlain now has (at least) $\$ 250,000$ more than each of the fans. Nozick thinks that these voluntary choices justify Chamberlain's wealth, and no interference should be enforced to his right to hold it. (Nozick, 2001, p. 161)

\subsection{Whose Liberty?}

Rawls and Nozick disagree about two things. First of all, there is a dispute about the liberty of whom. It seems that Rawls's original position, where the difference of talents and social status should be wiped out under the veil of ignorance, is too imaginary to persuade the people in real life to participate and accept the principle derived from it. There are two critiques from Sandel (Sandel, 1982): firstly, Rawls is committed to a thin, denuded notion of the person-a person separate from all ends, commitments, and capacities. If the moral subject is an individual, then the difference principle will involve the conscription of some people's talents in order to benefit the worst off; secondly, the difference principle thereby treats those subjects as means. (Baker, 1985)

The critiques point out that the selection under the veil of ignorance cannot happen in a real society, especially those who already know that they are rich and talented are reluctant to wipe out their memory and voluntarily agree to give up the benefits derived from their natural assets. Compared to Rawls, individuals in Nozick's theory, who know their natural assets and take advantage of them, can be seen everywhere in real life. It seems that his presupposition of individuals is more comfortable to access, and his theory protects everyone's liberty of entitlement. Besides, every individual's right is all that matters. He notes that the complete principle of distributive justice would simply say that a distribution is just if everyone is entitled to the holdings that they possess under the distribution. It seems that he regards all individuals as the end and try to guarantee all people's 
entitlement to the wealth legally produced by their labor. Nozick falls just short of supporting anarchy and then turns to the minimal state, which is the only legitimate form of a state where no individual's rights will be violated.

However, Nozick fails to recognize that his theory of entitlement can lead to a substantial violation of the liberty of the poor. As reported, in Hongkong, an extended housing crisis has put the possibility of purchasing a home out of the reach of many - and has made the cage home a reality for Hong Kong's poorest. Money flooding in from foreign investors looking for higher returns has exacerbated this rise. And landlords cut off many rooms into more cage homes to charge more rent. The example shows that the free market follows the capital rules. The poor voluntarily pay for the high cost in the whole process, and the rich pursue higher profits. It seems a fair deal, but the rich's liberty to obtain the surplus interfere with the poor because it prevents the poor from having a decent life. The expansion of the capital holder's business is squeezing the living conditions of the poor.

\subsection{Is the Natural Asset a Common Asset?}

The second disagreement between welfare liberals and libertarians is to what extent that natural talents should be considered a shared asset by a state. Rawls argues that the principles of justice are those which would be chosen by a rational agent behind a veil of ignorance. People do not know what place in society they will occupy, what their temperament will be, or what kind of economic, political, cultural or social order they will inhabit. However, Nozick thinks that talents should be regarded as private property, and individuals should be allowed to have the entitlement of their talents. Economic inequalities can be tolerated because people voluntarily pay for talented people's servings. (Jia \& Li, 2019)

I think natural endowments should also serve the whole society, not only benefits individuals' personal interest. Natural talent cannot only be regarded as personal private property. The first reason is that a person's success does not owe to individuals' efforts and owe to the state's education. To set the pilot as an example, a pilot bears the cost of acquiring and developing the flying technology. Simultaneously, the state and society's investment in education, scientific research, facilities, and other aspects of aerospace is enormous. (He, 2018) The second reason is that part of their payoff is taking advantage of the infrastructure. For Chamberlain's example, the affordable ticket price and the cost of commuting to watch the game may be one of the reasons to attract more people. The state's easy transport makes it possible for more people to come and watch; otherwise, its revenues will shrink.

What is worse, if we rely too much on the free market to price the natural talents, it will lead to value evaluation simplification. For example, when people think that being idols can make a lot of money by their beautiful appearances, more and more people want to be idols instead of choosing other jobs, such as scientists or police officers. Some would argue that scientists' payment will naturally rise when the market needs scientists. In scientific research, the inheritance of knowledge requires a constant influx of talented people and continuous financial support. The more fundamental problem is that the free market cannot justify why an actor's talent is more worthy than a scientist's talent. The wealth distribution in a free market sometimes cannot reflect the real value of a person's work.

\section{Resolution to the Dispute}

\subsection{MacIntyre's Resolution to the Dispute and the Flaw}

Nozick derives the conclusions from premises about the inalienable rights of each individual, while Rawls's two principles of justice are from the presupposition of the veil of ignorance and individuals' rational thinking under it. MacIntyre has no intention to support each of them. He thinks that Rawls and Nozick's moral debate is meaningless since there is conceptual incommensurability of the rival arguments. He says that "Rawls and Nozick reproduce the very same type of incompatibility and incommensurability at the level of philosophical argument that made A's and B's debate unsettable at the level of social conflict." (MacIntyre, 2007, p. 248) Both arguments are logically valid to be made so, but the rival premises are such that we possess no rational way of weighing one's claims as against another. The debates and disagreements reflect the culture so faithfully that its controversies turn out to be unsettable in just how the political and moral debates themselves are. Thus, the only way is to admit these disagreements and arrange public debate to enforce participation in the culture, searching for common stock of concepts and norms that all may employ and to which all may appeal.

He criticizes that Nozick and Rawls share the same social presuppositions that highlight the different life prospects and pursuits of good among individuals, but ignore that there is another way to solve people's dispute, which survives from that older classical tradition in which the virtues were central. (MacIntyre, 2007, p. 248) In Rawls's and Nozick's presuppositions, people in a society are just a collection of strangers, each pursuing their 
interests under minimal constraints rather than people in families, colleges, and other genuine communities who play a particular role and shoulder the respective responsibilities. Thus, he refuses to answer the question about what kind of social contract with others is it reasonable for individuals to enter into because this question excludes any account of the human community in which the notion of the desert is concerning contributions to that community's common tasks in pursuing shared goods. (MacIntyre, 2007, p. 250)

It is believed that the existence of the competing view is caused by the wrong presupposition that society is full of the limit set by our private and competing interests among individuals by MacIntyre. However, I think the separation between people is derived from the nature of modern society. People cannot reach a sympathetic understanding because they live in different cultural backgrounds and have different life experiences. It is hard to let two groups of people who share different life experiences fully sympathize with each other's opinions, regard others' interests as their self-interest, and admit others' contribution to society is equally essential. Thus, there will be problems with how to define the contribution, how to weight contributions. It is hard for MacIntyre to persuade both sides in the following scenario. For example, it is difficult for slave owners to admit that slaves play an essential role in food production for a country. At the same time, it is difficult for slaves to understand why slave owners can enjoy a luxurious life without any pure hard work. Differences of opinion arising from each party's self-interest, this phenomenon always exists in history and will inevitably continue to exist in the future.

MacIntyre asks for a human community in which the notion of the desert in relation to contributions to that community's common tasks in pursuing shared goods could provide the basis for judgments about virtue and justice. It may be easier to be achieved in an Aristotelian tradition where every individual has a given role and status within a well-defined and highly determinate system of roles and social positions. However, MacIntyre fails to recognize that it is hard for people who want to have equal political and economic rights to fight for their social status in modern society. For example, Slaves are not willing to be slaves but want to get equal rights with their masters, to pursue their own good, rather than the good told by their masters.

He thinks that we should find the common concepts and norms in our community. However, common concepts cannot sufficiently give justification to morality. If morality can only be accepted and explained under the framework of a particular culture, custom, or social purpose, it would be hard to ask every people in the world to agree on this moral argument. If morality can only represent a particular emotion or an attitude in a contextual scenario, for instance, can only be accepted by a specific mysterious religion but go against other people's interests, the premise of that morality should be questioned. For example, racism can be shared and admitted in a group of racists, but it cannot be justified as a moral attitude since it goes against ethnic groups' interests.

MacIntyre's approach to universally accepted ethics will encounter great difficulties; namely, the multicultural background makes the global ethical difficulty increase dramatically. There is no similar system in today's society to determine everybody's roles and related virtue as in Homeric society, especially given that people from each country have their own cultures, religions, and understanding of justice. MacIntyre thinks that those attempts to follow Kant in presenting the authority of the appeal to moral rules as grounded in the nature of practical reason fail. (MacIntyre, 2007, p. 62) However, I think that is the only way to construct a universal morality framework and solve conflicts in the public arena in a multi-culture background. Every system of virtue that individuals bring to the public arena from their cultures should be examined. In our society, we must establish a way to judge these moral claims and find a way to evaluate whether the premise of these arguments is just or unjust.

\subsection{The Moral Framework of Conciliation of Conflicting Liberties}

MacIntyre thinks that under the presuppositions of individualism, Rawls makes primary what is a principle of equality with respect to needs, while Nozick makes primary what is a principle of equality with respect to entitlement. It is true that Rawls defends the poor's need for basic needs while Nozick defends all individuals' entitlement to their labor. But as has been mentioned before, Nozick's theory has a flaw in that it ignores the conflict of the liberties between the rich and poor.

The idea of liberty favored by libertarians is negative liberty, which means the absence of interference by other people from doing what one wants or is able to do. Libertarians use the non-interference theory to defend the free market and no welfare state. But they fail to realize that not wiping out the influence of luck can lead to a harmful impact on the poor. If we fully accept every individual's liberty, we should put away no harm principle constraints to the poor. The rich have the right to expand their capital and sustain their surplus while the poor have the liberty to take from the rich for their survival since it is the rich who make their lives so difficult by conducting unjust commercials. If the existing system of private ownership makes their lives unsustainable, they 
should be allowed to have the right to fight. To avoid this rebellion caused by the inequality, we hope to design that a fair social principle will minimize the exploitation of labor by such a capital system so that those born in poverty can be least affected by the unequal factors in the exchange between capital and labor in a free market, so that their ability or diligence to work can be fairly evaluated.

Nozick does not provide a moral constraint on the liberty of the rich. He only mentions the moral constraints to argue that individuals have self-consciousness, rationality, free will, and they are moral agents who are capable of guiding its behavior by moral principles and capable of engaging in mutual limitation of conduct. (Nozick, 2001, pp. 48-50) He uses the concept of moral constraints to defend an individual's right to give meaning to his or her life only by exercising these capacities in accordance with some overall plan of his or her own.

A moral framework is given by Sterba to conciliate the conflict between the rich and the poor. He notes the conflicting liberties, saying that "the liberties of the poor, which is the liberty not to be interfered with in taking from the surplus resources of others what is required to meet one's basic needs, is morally preferable to the liberty of the rich, which is the liberty not to be interfered with in using one's surplus resources for luxury purposes." He applies the "ought" implies "can" principle to make the case more clear. (Sterba, 2009, pp. 285-287) In order to satisfy the liberty of the rich, the sacrifice to the poor is so great. These poor people who struggle for life may lose their lives. However, for the rich, the sacrifice is to give up the desire for luxury goods. Therefore, the rich are morally blameworthy for failing to make such a sacrifice.

Liberties of the rich should be constrained by the other liberty of the poor. Sterba shows a non-question begging argument for both sides. Premise (a) All individuals' liberties should be taken into account. Premise (b) there should be a constraint that is agreed upon by both sides in the conflict. Premise(c) No matter the rich or the poor would agree that sacrificing lives is too much compared to sacrificing their pleasure obtained by luxurious things. Therefore, there is no reason for the rich to deny their obligation to give up their surplus under the moral constraints of their right to liberty.

\section{Conclusion}

I shall provide another strategy to give a justificatory argument for redistribution by a welfare state. I think Nozick's wrong interpretation of labor and possession leads to his misunderstanding about which liberty all individuals are allowed to have. Another understanding of labor and entitlement can make the opinion that the right to liberty leads to the right to equality clearer.

In Rawls's theory, he distinguishes two kinds of liberty in his two principles. Of the two principles of justice, the principle of equal liberty applies to the allocation of rights and obligations, while the difference principle applies to the distribution of social and economic benefits. The first principle is the principle of equal liberty, saying that each person is to have an equal right to the most extensive total system of equal basic liberties compatible with a similar system of liberty for all. Rawls articulates the liberty principle, the most extensive basic liberty compatible with a similar liberty for others. The second principle is the difference principle, saying that social and economic inequalities should be arranged so that they are both (a) to the greatest benefit of the least advantaged persons and (b) attached to offices and positions open to all under conditions of equality of opportunity. (Rawls, 1971, p. 302)

The first principle has priority, compared to the second, and justice generally has priority over efficiency. As we can see, Rawls puts a constraint on social and economic equalities, which Nozick goes against. For Nozick, any distribution of "holdings", as he calls them, no matter how unequal, is just if (and only if) it arises from a just distribution through legitimate means. According to Nozick, anyone who acquired the property through the legitimate means is morally entitled to it. Therefore, the entitlement theory of justice states that the distribution of holdings in a society is just if and only if every person in that society is entitled to what he or she has.

But Nozick ignores that "holdings" does not equivalent to private ownership. Individuals have the entitlement of what they obtain legally by their labor. However, they don't have the right to have the full entitlement of them. The possession that comes from one's labor owes to that laborer's talent or ability and the supplier of the means of production. The means of production is divided into those possessed by individuals and those possessed by the public, even future generations. For example, unclaimed land is a means of production in public possession. One individual cannot claim to own it wholly because he or she cultivates it. This individual can only hold the fruit that has been cultivated with personal planting skills.

The natural talents can partly be seen as production in public possession. It is a long process from the potential to the realization of one's talent, in which education plays a significant role. Private school is not affordable to everyone, and the cost of public education has been dramatically reduced. Even though some people claim that 
they pay for the private school and don't own anything to the state, they may still benefit from the public education system because the teachers they have in private schools may receive education from the public schools. Besides, some people may argue that they have full entitlement to their inheritance. There is still tricky because the state provides guard and security so that inheritances can be obtained without being taken away. Nozick would agree with paying for this function of the state. But the essential question is how much should be paid by the rich and to what extent this money should be used on the welfare of the poor.

And the misunderstanding of the holding leads to an invalid transfer of once entitlements. However, supposing that we accept that there are no restrictions on voluntary transfers if I have some rights over a given resource, and I have and exercise the unrestricted moral power to transfer it to you, does it follow that you fully own the resource? It does not. I may not fully own the resource to start with, and the rights that I transfer to you may not be sufficient to give you full ownership. Even though the transfer is consensual, it is not entirely valid because the individual wrongly transfers the share of holding, which belongs to the public, not by the individual.

However, requiring equality does not mean that society's wealth should be redistributed equally to every individual. Individuals still can obtain more because of their talents in a specific area and sustain a part of their personal income to expand their business, as long as this difference would not deprive the equal economic opportunity for the disadvantaged.

I don't want to go that far to consider natural assets ultimately as a common asset shared by every individual. I agree with Rawls that economic inequalities may be tolerated if and only if they are to the benefit of the least advantaged group within society, which Rawls describes as those whose family and class origins are more disadvantaged than others, whose natural endowments permit to fare less well, or whose fortune and luck in the course of life turn out to be less happy. The wealth that society has generated from the talents of some individuals should be distributed in such a way that a portion of the rewards are given to individuals to motivate gifted individuals to continue to contribute to society; the other part should be distributed by the state to ensure that everyone can have a decent life.

\section{References}

Baker, C. E. (1985). Sandel on Rawls. University of Pennsylvania Law Review, 133(4), 895-928. https://doi.org/10.2307/3312128

He, R. (2018). Life, liberty, and the ability to work: whose rights, whether transferable. Studies in Ethics, (1), 93-99. https://doi.org/10.15995/j.cnki.1lxyj.2018.01.016

Jia, Z., \& Li, H. (2019). Self-ownership and distributive justice. Jilin University Journal Social Sciences Edition, 59(6), 187-198. https://doi.org/10.15939/j.jujsse.2019.06.zx4

MacIntyre, A. C. (2007). After virtue: A study in moral theory (3rd ed.). Notre Dame, Ind.: University of Notre Dame Press.

Meadowcroft, J. (2011). Nozick's critique of Rawls: Distribution, entitlement, and the assumptive world of A Theory of Justice. In The Cambridge Companion to Nozick's Anarchy, State, and Utopia (pp. 168-196). Cambridge University Press. https://doi.org/10.1017/CCOL9780521197762.011

Narveson, J., \& Sterba, J. P. (2010). Are liberty and equality compatible? New York: Cambridge Univ.Press.

Nozick, R. (2001). Anarchy, state, and utopia. Oxford: Wiley-Blackwell.

Rawls, J. (1971). A theory of justice (Original edition). Mass.: Belknap Press of Harvard University Press.

Sandel, M. J. (1982). Liberalism and the limits of justice. New York: Cambridge University Press.

Sterba, J. P. (2009). Ethics: the big questions (2nd ed.). Malden, MA: Wiley-Blackwell.

Vallentyne, P. (2011). Nozick's libertarian theory of justice. In The Cambridge Companion to Nozick's Anarchy, State, and Utopia (pp. 145-167). Cambridge University Press. https://doi.org/10.1017/CCOL9780521197762.010

\section{Copyrights}

Copyright for this article is retained by the author(s), with first publication rights granted to the journal.

This is an open-access article distributed under the terms and conditions of the Creative Commons Attribution license (http://creativecommons.org/licenses/by/4.0/). 